\title{
Study Regarding the Serum Level of Uric Acid and the Metabolic Syndrome
}

\author{
DANA EMILIA VELIMIROVICI ${ }^{1 *}$, MARIA RADA*, DELIA MIRA BERCEANU VADUVA ${ }^{1 *}$, MILAN DANIEL VELIMIROVICI ${ }^{2 *}$, \\ SIMONA DRAGAN ${ }^{1}$, DANIEL MARIUS DUDA SEIMAN ${ }^{1}$, DANIELA CIPU ${ }^{1}$, CORINA DUDA SEIMAN ${ }^{3}$, ADRIAN STANCU ${ }^{4}$, \\ MARCEL MIHAI BERCEANU VADUVA ${ }^{1}$ \\ ${ }^{1}$ University of Medicine and Pharmacy Victor Babes, Faculty of Medicine, 2 Eftimie Murgu Sq., 300041, Timisoara, Romania \\ ${ }^{2}$ Clinical Emergency Children's Hospital Louis Turcanu, 2 Dr. Iosif Nemoianu Str., 300011, Timisoara, Romania \\ ${ }^{3}$ West University of Timisoara, Faculty of Chemistry, Biology, Geography, 16 Pestalozzi Blvd., 300115, Timisoara, Romania \\ ${ }^{4}$ Faculty of Veterinary Medicine Timisoara, 119 Calea Aradului, 300645, Timisoara, Romania
}

The goal of this study is to investigate the relationship between the serum level of uric acid (UA) and metabolic syndrome (MetS) according to age and gender. The study included 395 patients (200 women and 195 men), with a mean age of $53.6 \pm 18$ years. Hyperucemia (HU) was defined by a serum level UA $\geq 7 \mathrm{mg} /$ $d L$ in men and $\geq 6 \mathrm{mg} / \mathrm{dL}$ in women (according to the EULAR guide), and MetS was defined according to the criteria of the International Diabetes Federation (IDF). The prevalence of hyperuricemia in the study lot was $17.21 \%$, and MetS was 35.44\%. In women, the prevalence of HU and MetS increases with age: $13.88 \%$ of women over 65 years show $\mathrm{HU}$, and $44.44 \%$ of them comprise the elements of MetS. In men, HU and MetS do not vary significantly depending on age. MetS has a higher prevalence in $\mathrm{HU}$ patients than in $\mathrm{HU}$-free patients. HU prevalence in MetS patients was 32.65\% in women versus $46.15 \%$ in men. In conclusions, the prevalence of HU and MetS differs significantly according to gender and age. The prevalence of MetS waS higher in male subjects of medium age and $\mathrm{HU}$ did not vary significantly depending on age. In women, the prevalence of $\mathrm{HU}$ and MetS was higher in those over 65 years. Hyperuricemia in middle-aged female patients can predict the MetS development.

Keywords: hyperuricemia, metabolic syndrome, age, gender, prevalence

Hyperuricaemia is a metabolic disorder characterized by increased blood levels of monosodium urate (salt of uric acid) due to the disruption of purine metabolism. Uric acid (UA) is the ultimate product of human purine metabolism and is primarily generated (approximately $2 /$ 3) by the enzymatic metabolism of endogenous purines (phosphoribosyl-pyrophosphate-synthase, hypoxanthineguanine-phosphoribosyl-transferase, xanthineoxidase), and secondary (approximately 1/3) of the purine food intake. Uric acid overproduction can occur in the following situations: excessive catabolism of nucleic acids (gout), mass production and destruction of cells (leukemia) or inability to excrete the final product (renal failure) $[1,2]$.

Uric acid is a heterocyclic compound: $\mathrm{C}_{5} \mathrm{H}_{4} \mathrm{~N}_{4} \mathrm{O}_{3^{\prime}}$ ( fig. 1).<smiles>O=c1[nH]c(=O)c2[nH]c(=O)[nH]c2[nH]1</smiles>

Fig. 1. Uric acid

For many years, uric acid has been regarded as a metabolically inertsubstance. However, there is increased evidence that uric acid has several actions that impact cellular metabolism. Thus, uric acid can behave as an endogenous antioxidantand a powerful collector of reactive oxygen species and hydroxyl radicals. Uric acid reacts with peroxynitrite and stabilizes nitric oxide synthase endothelial activity (eNOS) [3].

Its chemical limitations include the fact that uric acid can have antioxidant effect only in the presence of plasma ascorbic acid. In the absence of this, uric acid behaves paradoxically as a pro-oxidant and as an inflammatory factor. Uric acid works differently in the intra-cellular environment over the extracellular environment, where it is present in a soluble form. Although in extracellular fluids uric acid has a strong antioxidanteffect, in the intra-cellular environment it exerts nicotinamide-adenine-derived nicotinamide-adductin-mediated nicotinamide-oxidase (NADPH oxidase) mediated prooxidation effects [3].

In recent years, a number of evidence suggests that hyperuricemia may play a role in the development and pathogenesis of an increased number of metabolic diseases, including metabolic syndrome, hypertension, stroke and atherosclerosis. Hyperuricemia is generally a part of the group of metabolic and hemodynamic abnormalities, including abdominal obesity, glucose intolerance, insulin resistance, dyslipidemia and hypertension, all of which are often found under the term metabolic syndrome [4].

Although the role of hyperuricemia in cardiovascular and renal disease remains controversial, the results of recent studies show a strong relationship between elevated serum uric acid levels and the presence of metabolic syndrome. Not only associated, but also individually, hypertension, obesity, dyslipidemia, hyperglycemia and insulin resistance are positively correlated with serum levels of uric acid [59].

Hyperuricemia and the risk for metabolic syndrome (MetS) may vary depending on age and gender. Although hyperuricemia is generally considered to be a strong and independent predictor of MetS in both genders, a clear correlation has not been established. Despite epidemiological research demonstrating a positive relationship between the UA serum levels and MetS prevalence, prospective serum uric acid levels as a predictor of MetS prevalence are limited.

The purpose of this study is to investigate the relationship between serum uric acid (UA) and metabolic syndrome (MetS), differentiated by age and gender. 


\section{Experimental part}

\section{Material and method}

395 patients with cardiovascular risk factors were selected for cardiology consultations or outpatient internal medicine (Timisoara Circumvalatiunii Polyclinic) during 2016-2017, where waist circumference, body mass index (BMI) and blood pressure (BP) values were determined. It should be noted that the biological parameters (lipid profile, blood glucose levels, serum uric acid level) were noted on the analysis bulletins with which the patients presented at the consultation or were recommended to be performed by the treating physician. Biological parameters were determined in the same lab. Patients with a history of diabetes, dyslipidemia, hypertension, or treatment for these conditions previously diagnosed were included in the study.

Hyperuricemia has been defined as serum uric acid (UA) $\geq 7 \mathrm{mg} / \mathrm{dL}$ in men and $\geq 6 \mathrm{mg} / \mathrm{dL}$ in women according to the European League Against Rheumatism Guide (EULAR) [10].

Metabolic Syndrome (MetS) was defined according to the International Diabetes Federation (IDF) criteria [11]: -abdominal circumference $>94 \mathrm{~cm}$ in men and $>80 \mathrm{~cm}$ in women, or $\mathrm{BMI} \geq 25 \mathrm{~kg} / \mathrm{m}^{2}$;

$-\mathrm{TG} \geq 150 \mathrm{mg} / \mathrm{dL}$ or specific treatment for this type of dyslipidemia;

-HDL- cholesterol $<40 \mathrm{mg} / \mathrm{dL}$ in men and $<50 \mathrm{mg} / \mathrm{dL}$ in women or specific treatment for this type of dyslipidemia; -Hasting plasma glucose $\geq 100 \mathrm{mg} / \mathrm{dL}$ or type 2 diabetes mellitus diagnosed previously;

-BP $\geq 130 / 85 \mathrm{mmHg}$ or previously diagnosed hypertension under treatment.

\section{Exclusion criteria:}

-patients under 18 years of age;

BMI;

-patients without determined waist circumference or

-patients without determined the levels of serum uric acid, fasting plasma glucose and lipid profile; -alcoholic patients;

-the presence of other chronic conditions (invasive or non-invasive established atherothrombotic cardiovascular disease, malignant tumors, thyroid disorders, renal or hepatic impairment) that may have an effect on the analyzed parameters;

-patients who refused to be enrolled in the study.

395 patients with a mean age of $53.6 \pm 18$ years were enrolled in the study.

The included patients were divided into two groups: those who did not meet the criteria for MetS and those who met the IDF criteria for defining MetS.

\section{Statistical processing}

Data analysis was performed using the SPSS program. Descriptive data has been described as mean \pm SD. The statistics were conducted separately for men and women and for each age group. The normal variables were evaluated using the Chi-square test for the presence or absence of MetS and hyperuricemia. Differential analysis was used to test the correlation between MetS and UA. $p<0.05$ values were considered statistically significant.

\section{Results and discussions}

The general characteristics of the 395 patients included in the study are presented in table 1.

Of the 395 patients enrolled in the study, 200 (50.63\%) were women and 195 (49.36\%) men.

The 395 enrolled patients were randomized by age group (table 2), considering that the main objectives of this study was to determine the prevalence of metabolic syndrome
Table 1

CHARACTERISTICS OF PATIENTS

\begin{tabular}{|l|l|}
\hline Parameters & $\begin{array}{l}\text { Mean } \pm \text { DS/Procent } \\
(395 \text { patients ) }\end{array}$ \\
\hline Age (years) & $53.6 \pm 18$ years \\
\hline Gender M/F (\%) & $49.36 / 50.63$ \\
\hline BMI (kg/m²) & $31.2 \pm 5$ \\
\hline Waist circumference (cm) & $98.5 \pm 15$ \\
\hline Triglycerides (mg\%) & $168.4 \pm 45.62$ \\
\hline HDLc (mg\%) & $42.72 \pm 10$ \\
\hline Blood sugar levels (mg\%) & $95.2 \pm 22.78$ \\
\hline TAS (mmHg) & $136.08 \pm 18.5$ \\
\hline TAD (mmHg) & $85.5 \pm 10.9$ \\
\hline Uric acid (mg\%) & $5.85 \pm 1.8$ \\
\hline
\end{tabular}

Table 2

DISTRIBUTION OF PATIENTS BY AGE GROUP

\begin{tabular}{|l|c|c|c|}
\hline Age & $\leq 44$ years & $\mathbf{4 5}-\mathbf{6 4}$ years & $\geq 65$ years \\
\hline No. patients (\%) & $76 \mathrm{p}(19.24 \%)$ & $236 \mathrm{p} \mathrm{(59.74 \% )}$ & $83 \mathrm{p}(21.01 \%)$ \\
\hline
\end{tabular}

and hyperuricemia by age and gender groups. The mean age of the enrolled patients was $53.6 \pm 18$ years; patients under the age of 18 were excluded from the study.

Middle-aged patients (45-64 years) are the majority: $59.74 \%$. In approximately equal proportions are represented the patients $\geq 65$ years $(21.01 \%)$ and those aged $\leq 44$ years $(19.24 \%)$.

The data are consistent with those found in Chiou et al., where both middle-aged female and male patients were predominated [12].

Another aspect in the paper was the determination of MetS prevalence in the entire batch as well as its prevalence according to gender and age (by age group).

Of the 395 enrolled patients, 140 patients (35.44\%) met the IDF criteria for defining the metabolic syndrome, a percentage comparable to literature data where the MetS prevalence was $30.1 \%$ and $39.3 \%[13,14]$. The data is shown in figure 2 .

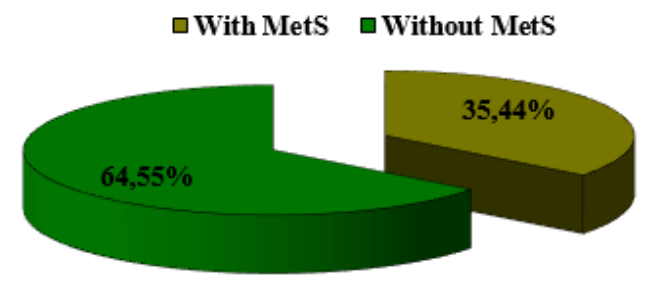

Fig. 2. MetS prelevance

It is established that MetS affects over $25 \%$ of the general population, and about tw o-thirds of MetS patients are predisposed to a cardiovascular event. Worldwide, IDF estimates that approximately $20-25 \%$ of the adult population can be classified as MetS subjects (www.idf.org), causing an increase in the frequency and severity of cardiovascular disease [15]. 
Although the MetS prevalence of the studied group was $35.44 \%$, higher than that reported by IDF, data from a recently published study (conducted on a population in Serbia, the Vojvodina region, a population similar to that in our region, Banat) indicates a much higher prevalence of MetS, of $50.64 \%$ [16].

Hyperuricemia, per se, is prooved to be an independent predictor for atherosclerosis in patients with hypertension. Recent clinical studies have shown that serum uric acid levels are associated with subclinical atherosclerosis, especially in men with type 2 diabetes [3].

In this paper the prevalence of hyperuricemia was also studied, as well as its prevalence in patients with and without MetS.

The prevalence of hyperuricemia among the patients enrolled in the study was $17.21 \%$, as shown in figure 3.

$\square$ With HU $\square$ Without HU

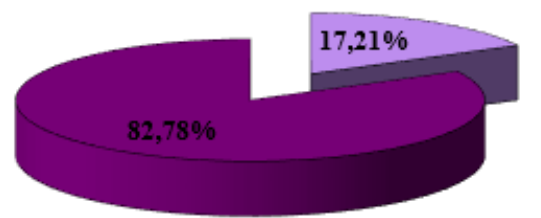

Fig. 3. Prelevance of hyperuricemia

The prevalence of hyperuricemia increases with agt as demonstrated by the study of Liu et al.: the prevalenc of hyperuricemia in the study population (age $>60$ years was $16.7 \%$ [ 14$]$.

Another aspect of the paper was the gender and ag group analysis of MetS distribution and hyperuricemia.

In women, MetS prevalence increases with age, $44.44^{\circ}$ for the age group over 65 years compared to $22.48 \% \mathrm{fc}$ the $45-64$ years age group and $11.42 \%$ for those aged $\leq 4$ years (fig. 4).

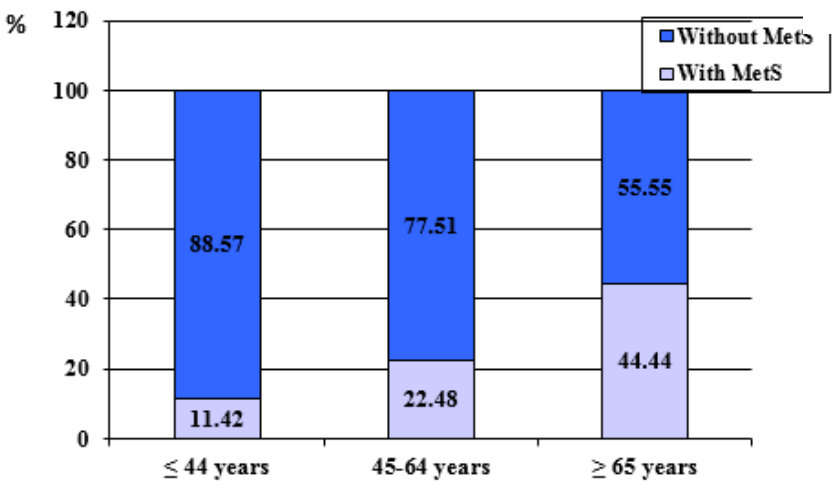

Fig. 4. MetS prelevance on age groups at women

Data from literature also shows that the prevalence of MetS in women increases with age, this increase being more significant after 50 years [17]. Also in the study conducted by You and collaborators, MetS's prevalence increased progressively, with age, in women: those younger than 35 years rarely met MetS criteria, while in women over 60, the MetS prevalence was higher than that observed in males [18].

In male patients, MetS prevalence was higher in the age group of $45-64$ years (49.53\%), followed by the age group $\geq 65$ years (44.68\%) and that $d^{\prime \prime} 44$ years $(41.46 \%)$ (fig. 5).

Chiou et al. showed the percentage of male subjects with MetS increased with the age increase until the age of 55 years; at this age $35.4 \%$ of men developed MetS. After the age of 55 years, the percentage of men with MetS decreased slightly with age, butcontinued to increase with increasing age in women [12].

Another clinical trial shows that MetS prevalence 3020

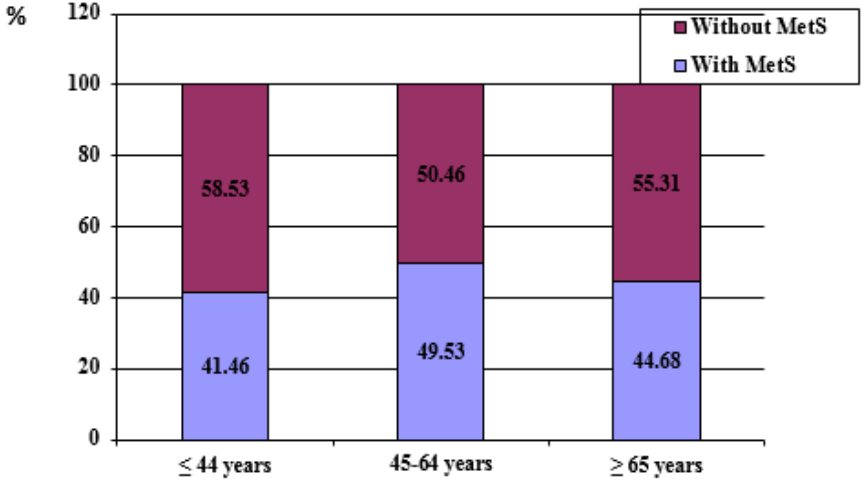

Fig. 5. MetS prelevance on age groups at men

increases gradually by age up to 60 years, after that it has the tendency to decrease [17].

The prevalence of hyperuricemia in women also increases with aging: $13.88 \%$ of women aged 65 years were hyperuricemic, while in women between 45-64 years, hyperuricemia was present in $9.30 \%$ of subjects, compared to $5.71 \%$ in women $\leq 44$ vears (fiq. 6).

$\%$

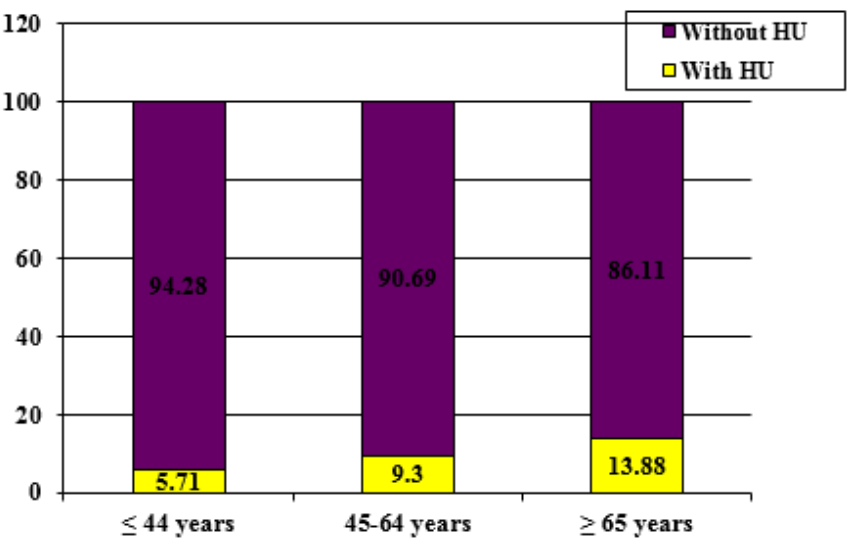

Fig. 6. Prelevance of HU by age group at women

As a particular aspect in women, the uric acid level remains constant until the menopause, and then it begins to rise to the level found in men of comparable age. This is explained by the fact that estrogen favors the excretion of uric acid during the reproductive period.

Older age influences the occurrence of hyperuricemia through several mechanisms: impairment - reduction of renal function, use of diuretics and other drugs that alter uric acid clearance, connective tissue changes and degenerative osteoarticular lesions favoring the formation of monosodic urate crystals.

Wu etal. Found that the prevalence of hyperuricemia in women was $4.8 \%$ in those aged $40-44$ years, and it increased to $25.3 \%$ in those women over 80 years [17].

In men, the prevalence of hyperuricemia varies insignificantly by age groups. Thus, it was $21.95 \%$ for the age group under 44 years compared to $26.16 \%$ for men between $45-64$ years, and $25.53 \%$ in those over 65 years (fig. 7).

In the study of Wu etal., although the overall prevalence of hyperuricemia was higher in men (15.7\%) than in women $(12.3 \%)$, the prevalence of hyperuricemia according to age group was different in the two genders: in men, the prevalence of hyperuricemia remained stable with age [17].

Actual literature data shows that although the prevalence of hyperuricemia and that of MetS is different according to age and gender, it is higher in male subjects compared to females, especially in young and middle-aged subjects [ 17 , 19- 22]. 


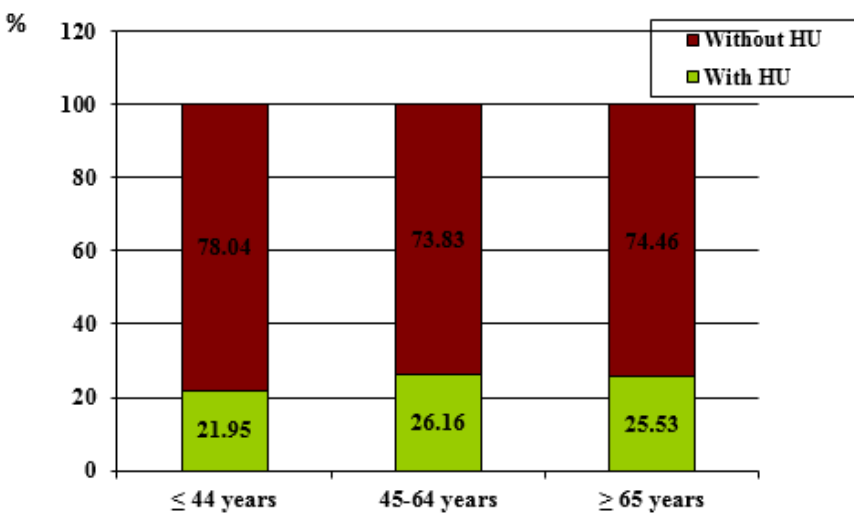

Fig. 7. Prelevance of HU by age group at males

Hyperuricemia should be considered as a component of MetS and as a risk factor for cardiovascular diseases. According to the latest blood pressure management guideline of the European Society of Cardiology, the serum level of uric acid is listed as cardiovascular risk factor next to traditional cardiovascular risk factors [23].

Hyperuricemia is metabolic disorder that can be considered as a possible defining marker in those with metabolic syndrome. An elevated serum uric acid level was associated with an increased risk of MetS. There is a positive association between serum uric acid and metabolic syndrome and a positive correlation between the individual components of metabolic syndrome with uric acid [24].

Hyperuricemia should be considered as a component of the metabolic syndrome and a risk factor for cardiovascular disease. Hyperuricemia has a higher prevalence in MetS patients than in non-MetS patients [24]. The link between MetS and hyperuricemia is insulin resistance and consecutive hyperinsulinism.

Another objective of the paper was to determine the prevalence of hyperuricemia in patients with MetS.

Of the 140 patients who met MetS criteria, 58 patients were also $\mathrm{HU}$ and 82 had normal uric acid values, so HU prevalence in MetS patients in the study group was $41.42 \%$.

Table 3

HU PRELEVANCE AT METS PATIENTS, DIFFERENTIATED BY GENDER

\begin{tabular}{||l|l|l||}
\hline \hline Gender & \multicolumn{1}{|c||}{$\begin{array}{c}\text { Women with MetS } \\
\text { number=49 }\end{array}$} & $\begin{array}{c}\text { Men with MetS } \\
\text { number=91 }\end{array}$ \\
\hline Cu HU & $16(32.65 \%)$ & $42(46.15 \%)$ \\
\hline Fără HU & $33(67.34 \%)$ & $49(53.84 \%)$ \\
\hline
\end{tabular}

The gender-differentiated analysis of $\mathrm{HU}$ prevalence in patients with MetS is shown in table 3.

The prevalence of hyperuricaemia in patients with MetS was $41.42 \%$. According to gender, in the batch included in the study, the prevalence of hyperuricemia was higher in male patients $(46.15 \%)$ versus the prevalence in women (32.65\%). Both the prevalence of hyperuricemia and MetS was higher in male subjects.

MetS's prevalence increases with elevated serum uric acid levels. The higher the serum acid uric levels are, the higher is the prevalence of MetS.

Chiou and colleagues showed that although the prevalence of hyperuricemia was similar in elderly men and women, women with hyperuricemia had a higher prevalence of MetS than men with hyperuricemia. In the same study, the prevalence of subjects with MetS and hyperuricemia increased significantly in women aged 45-
64 years and over 65 years, but not in men, most likely because MetS and its components developed more frequently after menopause, due to the decrease in uricosuric effect of estrogen [12].

Literature data showed that serum uric acid levels had been closely associated with the presence of MetS, more pronounced in women than in men, and it has been observed that the highest risk for MetS is for middle-aged women with hyperuricemia [12].

Epidemiological studies over the last five decades have confirmed an association of elevated uric acid levels with cardiovascular diseases, although not all agree that this correlation is independent of other risk factors. Among all the factors that influence the activity of uric acid in its relation to cardiovascular diseases (coronary, cerebral, peripheral arterial), vascular nitric oxide plays a cardinal role $[25,26]$.

Based on several studies, both epidemiological and clinical, there have been findings that suggest that hyperuricemia is a risk factor for cardiovascular disease byinducing endothelial dysfunction, proliferation of smooth muscle cells in the blood vessels, the stimulation of inflammation and atherosclerosis, leading finally to clinical manifestation of coronary ischaemia.

\section{Conclusions}

Uric acid is a potential marker of the metabolic syndrome. Metabolic syndrome and hyperuricemia are considered to be important risk factors for cardiovascular disease through inflammatory processes that can lead to more rapid development of atherosclerosis.

The prevalence of hyperuricemia and MetS differs according to gender and age. Serum uric acid levels correlate positively with MetS and are more closely associated with its presence in males than at women. The prevalence of MetS and hyperuricemia was higher in male patients compared to their prevalence in women.

In middle-aged male subjects, the prevalence of MetS was higher, whereas the prevalence of hyperuricaemia did not vary significantly with age. In contrast, in women, the prevalence of hyperuricemia and MetS increases with age, estrogen favoring the excretion of uric acid during the reproductive period. Hyperuricemia among middle-aged women can predict the development of MetS.

Despite epidemiological research demonstrating a positive relationship between serum uric acid and MetS prevalence, prospective studies regarding serum uric acid levels as a predictor of MetS incidence are limited, this motivating the present study.

\section{References}

1.REZUS, E., LEON CONSTANTIN, M.M, REZUS, C. Rev. Chim. (Bucharest), 66, no. 7, 2015, p.1015-18.

2.DUSE, A. O., BERCEANU VADUVA, D., NICOLOV, M., TRANDAFIRESCU, C., BerceAnU VAduVA, M., CEVEI, M., HEGHES, A. Rev. Chim.(Bucharest), 68, no. 6, 2017, p.1234

3.BILLIET, L., DOATY, S., KATZ, J.D., VELASQUEZ, M.T. ISRN Rheumatology, vol. 2014, Article ID 852954, p. 7.

4.CHOI, H. K., AND FORD, E. S. The American Journalof Medicine, 120, no. 5, 2007, p. 442-447.

5.LIN, S.D., TSAI, D.H., AND HSU, S.R. J ournal of the Chinese Medical Association, 69, no. 11, 2006, p. 512-516.

6.ONAT, A., UYAREL, H., HERGENC, G., ET AL. American J ournal of Hypertension, 19, no. 10, 2006, p. 1055-1062.

7.KAWADA, T., OTSUKA, T., KATSUMATA, M. AND SUZUKI, H. J ournal of the Cardiometabolic Syndrome, 2, no. 3, 2007, p. 158-162.

8.BHOLE, V., CHOI, J.W., KIM, S.W., DEVERA, M. AND CHOI, H. The American J ournal of Medicine, 123, no. 10, 2010, p. 957-961. 
9.VELIMIROVICI, D.E., BERCEANU-VADUVA, D., CIPU D., VELIMIROVICI, M., BAIBATÃ, D.E., COSOR, O., STANGA, L., GOGOASA, I., RADA, M. Rev Romana Med Lab,supliment la vol. 25, nr. 2, 2017, p.119-120. 10.NUKI, G., DOHERTY, M., RICHETTE, P. Pol Arch Intern Med, 127 no. 4, 2017, p. 267-277.

11.ALBERTI, K.G., ZIMMET, P., SHAW, J. Lancet, 366, 2005, p. 1059-1062 12.CHIOU, W. K., WANG, M.H., HUANG, D.H. ET AL.J Epidemiol 20, no.3, 2010, p. 219-224

13.ZIAEE, A., ESMAILZADEHHA, N., GHORBANI, A ET AL. Global J ournal of Health Science. 5, no. 1, 2013, p. 155-165

14.LIU, M., HE, Y., JIANG, B. ET AL. International J ournal of Endocrinology. 2014: article ID754678, 11 pages.

15.POPA, E., COMAN, A., TRAIAN, M., PETROVANU, R. Actualitati în patogenia sindromului metabolic. Rolul PPAR - alpha in modularea raspunsului inflamator. www.academia.edu

16.POPOVICI, D.S., STOKIC, E., TOMIC-NAGLIC, D. ET AL. Diabesity 1, no. 3, 2015, p. 24-28..

17.WU, W.H., YU, H.K., LIN, R.S. ET AL. Chun Shan Medical J ournal, 23, 2012, p. 11-20.
18.YOU, L., LIU, A., WUYUN, G ET AL. J of Atherosclerosis and Thrombosis, 21, no. 4, 2013, p. 355-365.

19.RADA, M., VELIMIROVICI, D.E., BERCEANU VADUVA, D., DUDA SEIMAN, D.M., GOGOASA, I., MANCAS, S. Romanian Heart J ournal, supplement, 2015, p. 47-48.

20.STANCU, A., CARPINISAN, L., GHISE, A., PENTEA, M., BERCEANUVADUVA, D.M., VELIMIROVICI, D.E., ROMEO, C. Mat. Plast., 54, no. 3, 2017, p. 546-548

21.STANCU, A., GHISE, A., PENTEA, M, VELIMIROVICI D.E., CARPINISAN, L., CRISTINA, R., Mat. Plast., 54, no. 4, 2017, p. 785-787 22.STANCU, A., GHISE, A., PENTEA, M, VELIMIROVICI D.E., CARPINISAN, L., CRISTINA, R., Mat. Plast., 54, No. 2, 2017, p. 302-303, 23.WILLIAMS, B., MANCIA, G., SPIERING, W., et al. European Heart J ournal, 39, 2018, p. 3021-3104.

24.BHAGAT, R., KISHORE, K., KUMAR, A. J ournal of Health Sciences 1, no. 1, 2015, p. 26-31

25.CIPU, D., BERCEANU-VADUVA, D.M., VELIMIROVICI, D.E., CIPU, D. S. Rev. Chim. (Bucharest), 67, no.6, 2016, p.1218-23.

26.STRASAK, A.M., KELLEHER, C.C., BRANT, L.J ., RAPP, K., RUTTMANN, E., CONCIN, H., ET AL. Int J Cardiol., 125, 2008, p. 232-9.

Manuscript received: 14.03 .2018 